\title{
Pyrolysis of Low Rank Lignites
}

\author{
A. Koyun*, A.B. Hazar Yoruc, D. Ceylan Erdogan and E. Ahlatcioglu \\ Yildiz Technical University Science and Technology Research and Application Center, Yildiz, Turkey
}

\begin{abstract}
In this study, six different Turkish coals were studied. One of them was Zonguldak coal and the others were low rank Turkish lignites. The amount of the pyrolysed gases of the coal as $\mathrm{CH}_{4}, \mathrm{C}_{3} \mathrm{H}_{8}, \mathrm{CO}, \mathrm{CO}_{2}, \mathrm{SO}_{2}$ were determined from the experiments by using several first order reaction models that include energy distribution and the activation energy distribution during the pyrolysis was calculated at the same time. The results of pyrolysis experiments of coals were examined by means of several first order reaction models that include energy distribution. The tar amounts and overall conversion of six different coals, activation energies of nine volatile components output, standard variation values that belong to their energy distribution, maximum quantity of product of each component and molecular collision coefficients were determined. As a result of using these variables in the model equations, conversion quantities for all of the compounds of six types of coals and variation of activation distribution functions with respect to the kinds of coals were presented graphically with a comparison of the cited data in references.
\end{abstract}

DOI: 10.12693/APhysPolA.123.396

PACS: $51.30 .+\mathrm{i}$

\section{Introduction}

Pyrolysis is a process releasing of soluble volatile matters in a coal at the fluidized state with an inert gas. Studies on the coal can be interpreted as a research working to supply of energy demand of any country from their own sources. Although various studies are held in Turkey, that have significant quantity of low-rank coal sources, about her lignite sources, in many of these studies no result has been aimed to produce the know-how directed for the project design [1].

The coal is a complex form that contains hydrocarbon and aromatic compounds of $\mathrm{O}, \mathrm{N}, \mathrm{S}$ atoms. Heating process causes deformation of this structure. Volatile components move out of the coal when bonds break off at different temperatures. Pyrolysis is deformation of the organic compounds by heating with steam and/or inert gas [2].

Mathematical definition of the conversion is shown as follows:

$$
\mathrm{d} V / \mathrm{d} t=k\left(V-V^{*}\right) .
$$

$V^{*}$ determines the volatile quantities by the function of dry coal. A variety of models are suggested for the pyrolysis process. When Anthony [3] and Howard [4] define the pyrolysis as competition reaction model, Reuther [5] defines it as first order reaction model. These models cannot determine the kinetic coefficient by a standard method. Therefore if thermal degradation of the coal is taken as a variety of independent chemical reactions. The difference of the strength of chemical bonds of molecules will make a difference on the degradation temperature of bonds and activation energies of components during the pyrolysis will show change. The general definition of the activation energy is as follows:

Many first order reaction models that are chosen for application in this study were first situated by Pitt [6].

\footnotetext{
*corresponding author; e-mail: koyun@yildiz.edu.tr
}

Pitt [6] and Anthony [3] used Gauss distribution in their studies.

$$
\begin{aligned}
& F_{i}(E)=\frac{1}{(2 \pi)^{1 / 2} \sigma} \exp \left(-\frac{1}{2 \sigma^{2}}\left(E-E_{0}\right)^{2}\right), \\
& \int_{0}^{\infty} F(E) \mathrm{d} E=1 .
\end{aligned}
$$

The potential volatile material amounts that release between two activation energies like $E$ and $E+\mathrm{d} E$ are calculated by using Eq. (4):

$$
\mathrm{d} V^{*}=V^{*} F(E) \mathrm{d} E .
$$

Therefore the reaction rate of each volatile component can be determined by using Eq. (1) for each component

$$
\frac{\mathrm{d} V_{i}}{\mathrm{~d} t}=k_{i}\left(V_{i}^{*}-V_{i}\right)
$$

At the isotherm temperature conditions the integral of this equation gives the volatile component amount

$$
V_{i}^{*}-V_{i}=V_{i}^{*} \exp \left(-k_{0 i} t \exp \left(-E_{i} / R T\right)\right)_{i} .
$$

The total volatile substance amounts can be calculated by all of the values that are used in Eq. (2) and Eq. (4).

$$
\frac{V^{*}-V}{V^{*}}=\int_{0}^{\infty} \exp \left(-k_{0} t \exp (-E / R T)\right) F(E) \mathrm{d} E \text {. }
$$

For the parametric temperature, the equation can be written as below

$$
\frac{V^{*}-V}{V^{*}}=\exp \left(-\int_{0}^{t} k \mathrm{~d} t\right) F(E) \mathrm{d} E .
$$

So the thermal degradation of the coal can be determined by using Eq. (2) and Eq. (8) and the model of the pyrolysis process will be able to define by using these equations.

\section{Experimental and results}

In this study the volatile material amounts of each volatile gas component that come out by the pyrolysis of the six different coals were investigated. The gas components that can occur in each sample and their maximum percentage were determined. Activation energy distribution was calculated by using the results of pyrolysis 


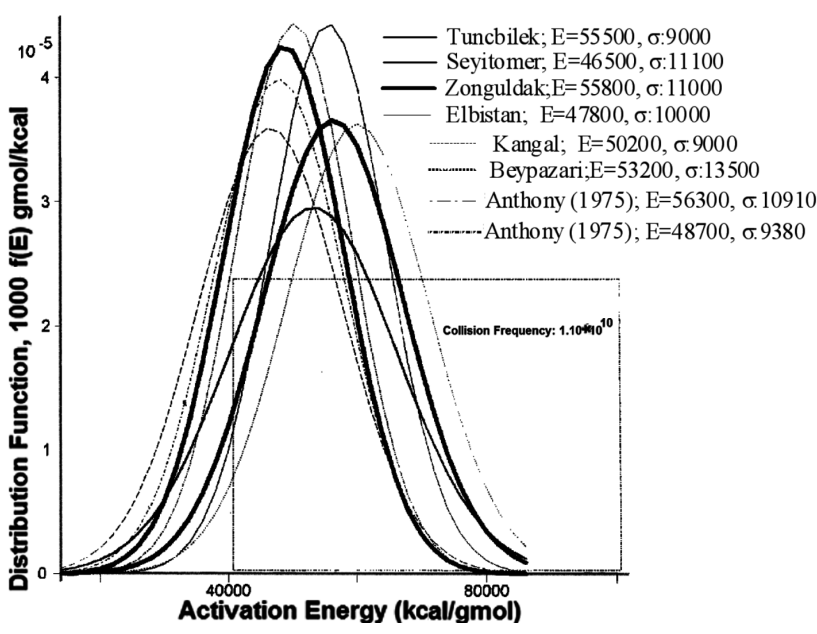

Fig. 1. The energy integral limit values of the coals. The collision frequency of Zonguldak coal is $1.10 \times 10^{10}$; the collision frequency of the other coals is $1.67 \times 10^{13}$.

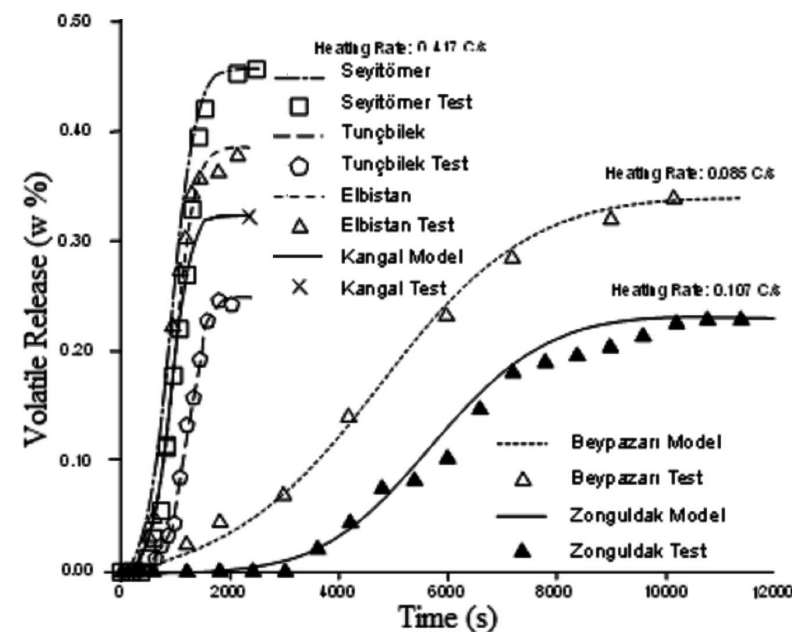

Fig. 2. Total conversions of Seyitomer, Tuncbilek, Elbistan, Kangal, Beypazari, and Zonguldak lignites.

experiments. In order to apply the activation energy distribution model, the $V^{*}$ values in Eq. (2) Eq. (7) and
Eq. (8) were calculated from the results of the experiments. $V^{*}$ values depend on the last temperature at the pyrolysis process and the type of the coal.

After getting the releasing amount of the pyrolysed gases, the $\mathrm{d} x / \mathrm{d} t$ values were calculated and the activation energy distribution model [3-5] was used to define the average activation energy $\left(E_{0}\right)$ and standard deviation $(\sigma)$ for six different coals.

It has been compared with some other coals $E_{0}$ and $\sigma$ values (Fig. 1). Zonguldak lignite has the highest activation energy among six coals. This situation was examined and it was investigated that activation energy is influenced from rank of the coal.

The total and species conversion of the coals were determined during the pyrolysis reactions (Fig. 2). As a result, the conversion rates and the quantity of the pyrolysed gases of Tuncbilek are lower than Seyitomer, Elbistan, and Kangal lignites. Zonguldak coal is also conversed with a lower rate than the other coals.

If the heating rate is taken as $0.417^{\circ} \mathrm{C} / \mathrm{s}$ for the conversion of Zonguldak and Beypazari lignite, it is seen that the conversion of Zonguldak lignite is the slowest and reaction rate of this coal is slower than the other five coals. The activation energy of the Zonguldak is higher than the others.

Although the reaction rate constants of some coals were near each other, the conversion of Zonguldak lignite is also different here.

\section{References}

[1] S. Eser, Ph.D. Thesis, Middle East Technical University, 1978.

[2] A. Koyun, Ph.D. Thesis, Yildiz Technical University, 1995, p. 44.

[3] D.B. Anthony, Fuel 55, 121 (1976)

[4] J.B. Howard, in: Chemistry of Coal Utilization Ed. M.A. Elliot, Wiley, New York 1981, Ch. 12, p. 665.

[5] J.J. Reuther, D. Ralph, J.J. Warcholl, J.A. Witherm, Fuel 63, 630 (1984).

[6] G.J. Pitt, Fuel 41, 267 (1962). 